\title{
Woodchuck Hepatocellular Carcinoma
}

National Cancer Institute

\section{Source}

National Cancer Institute. Woodchuck Hepatocellular Carcinoma. NCI Thesaurus. Code C124251.

Hepatocellular carcinoma (HCC) occurring in a woodchuck, usually as a result of chronic infection by the woodchuck hepatitis virus. The woodchuck model of viral-induced HCC provides an animal model that resembles the complex human liver environment of HCC in the context of chronic hepatitis B viral infection. 